\title{
I Major Western Views of Nature
}

To demonstrate that pre-evolutionary views of human nature persist and still dominate thinking about human beings, a necessary first step is to differentiate clearly between pre-evolutionary and evolutionary views of the biological world. In arguments about these issues a clear understanding of the differences between these views is usually assumed to exist; yet the crux of the differences is not clear to a great many of us.

Thus Part I sets out the pre-evolutionary and evolutionary views and tries to sharpen our sense of the minimum requirements that must be met if a view is to be called evolutionary. The crux of the difference between pre-evolutionary and evolutionary views centers on their conception of the categories of things in the biological realm. Preevolutionary thinkers asserted the existence of fixed natural categories. Evolutionism construes the biological world as a dynamic system composed of ever-changing species.

No amount of accommodative goodwill can reconcile these two views comfortably. And from these differences arise greater differ- 


\section{Major Western Views of Nature}

ences in the understanding of the broad historical processes that have resulted in life as we know it and that will continue to operate whether we wish them to or not. 


\section{Humoral/Environmental Theories and the Chain of Being}

Current arenas in the ongoing conflict over the relationship between nature and culture are easy to locate. The terms of debate are familiar because there is a general consensus about the relevant theories and evidence to be discussed. The semantic and lexical impact of evolutionism is strong and provides the needed signposts. But before evolutionism, comparable discussions of the human condition employed different terminologies and styles of argument.

The pre-evolutionary literature dealing with "human nature" and its social, political, ethical, and theological consequences spans the whole Western tradition. Nevertheless, it is difficult to find contemporary analytical discussions that focus directly on these biological issues because of the tendency to dematerialize the material/biological dimensions of important philosophical works and to forget how concerned major thinkers have been with exceedingly mundane problems. The history of biological and medical thought, for example, is often treated separately from the history of Western philosophy. ${ }^{1}$ 
Naturalistic Views of Society

My choice of materials is guided by some specific assumptions about the necessary contents of any naturalistic view of society, evolutionary or not. Any such view provides answers to the following questions:

I. What exists in the world and how is it organized?

2. How much of the outside world is found inside of human beings?

3. Are humans an entirely special form of creation, or are we constituted of the same matter as all the other things in the cosmos, differing from other life forms only in organization? If it is assumed that humans are composed of the same matter as everything else in the world, a fourth question then arises:

4. How does what is outside in the world get inside of human beings? This question centers on the mixed sources of heredity and environment as they influence human structure and behavior.

5. Is matter from the outside world altered in any way when it is found inside of human beings? This question involves a complex of ideas about the transformation of the primary constituting properties of matter into blood, bone, and tissue as manifested in a human body.

The final question is complexly theological and theoretical:

6. What is left of a human being if all matter from the outside world is removed? Centering on the host of issues about the mind and the soul, this question includes others about the organizational principles that give humans particular characteristics and whether or not these organizational principles are intrinsic aspects of physical matter.

A naturalistic view of society thus provides an explanation of the origin, structure, and behavior of living things and then places humans within that context. It does so against the backdrop of a theory of the structure and operation of the material universe. Darwin's theory of the origin of species and the descent of humans is one such theory.

Before Darwin, a combination of ideas about the material structure of the universe, its relation to the structure and behavior of human beings, and the origin of the entire system dominated Western thought from the fifth century B.C. onward. This tradition includes theories 
about the physical elements of the universe, their effect on the humoral constitution of human beings, and the origins of the separate categories of living things (i.e., the "origin of species").

A caveat is needed. Over two millennia of Western thought are compressed into a simple mold here. This necessary simplification makes it difficult to see that the attractiveness of these ideas lay precisely in their ability to organize the complex world of experience into intelligible categories for thought and action. A much more elaborate discussion of these issues is available in Ernst Mayr's Growth of Biological Thought (1982).

\section{Humoral/Environmental Theories}

Humoral/environmental theories form an intriguing and complex explanatory system linking the universe, the earth, humans (as a group and as individuals), and even historical events into a single overall scheme. Simultaneously they provide practical guidelines for conduct. These systems are based on meticulous, consistent observations of the physical, biological, and cultural worlds. They assert that the world is orderly and that it can be studied by systematic means.

The fundamental materialism of this tradition makes a clear appearance in the great medical texts of antiquity. Soon thereafter the separation between material and moral causes of temperament and disease ramifies into a fully developed empirical tradition (Laín Entalgo 196I).

The humoral/environmental theories are always emphatically nonevolutionary. They offer no dynamic, material explanation of the origins of the categories of living things or any continuing process by which new categories come into being. Early on, the species are the work of a variety of gods or processes of interbreeding; later they are produced by the God of Genesis.

The power of these humoral/environmental theories is amply demonstrated by their durability. When in the eighteenth century the Spanish medical thinker Martín Martínez made a thorough critique and attempted renewal of medicine, he expressed his ideas in two volumes 
of dialogues between a chemist, a follower of Hippocrates, and a follower of Galen. Knowledge of Hippocratic and Galenic texts makes most of Martínez' arguments-and those of his English, French, German, and Italian colleagues-quite intelligible despite the many centuries and scientific discoveries that separate them. Qualities, elements, and humors were as fundamental to eighteenth-century thought as they were in antiquity; these ideas persisted through the Arabic renderings of Galen and other classical writers until the originals were rediscovered during the Renaissance.

The basic structure of ideas consists of sets of dual oppositions. Figure I charts their interrelationships. According to their structure of ideas, the material world is divided into primary qualities, elements, and humors. The primary qualities are not themselves manifested directly in matter; rather they are the fundamental characteristics that cause the various compositions of matter in the perceivable world. These qualities are arrayed as two sets of dual oppositions: hot/cold and dry/moist. Everything in the world is a material manifestation of combinations of these primary qualities. The basic elements of perceivable matter-earth, air, fire, and water-result from the differing combinations of the primary qualities. Dry and cold yields earth; moist and cold, water; moist and hot, air; and hot and dry, fire. All things in the material universe are made up of varying combinations of these four elements, which in turn are combinations of the primary qualities.

When these four elements combine to form organic beings, they are converted from elements into humors. These substances that constitute organic beings retain the properties of the elements that give rise to them. In a living body, fire yields yellow bile; air becomes blood; earth becomes black bile; and water yields phlegm. All beings are made up of particular combinations of these four humors. Every species and individual has its particular humoral makeup.

Each of the humors has a direct behavioral counterpart in this complex cultural system. Personal characteristics are explained by reference to the predominance of certain humors and the actions of these humors are explained by their elemental makeup. Direct material causation of physical and behavioral states is thus assumed. The predominance of yellow bile (fire, hot and dry) leads to choleric behav- 


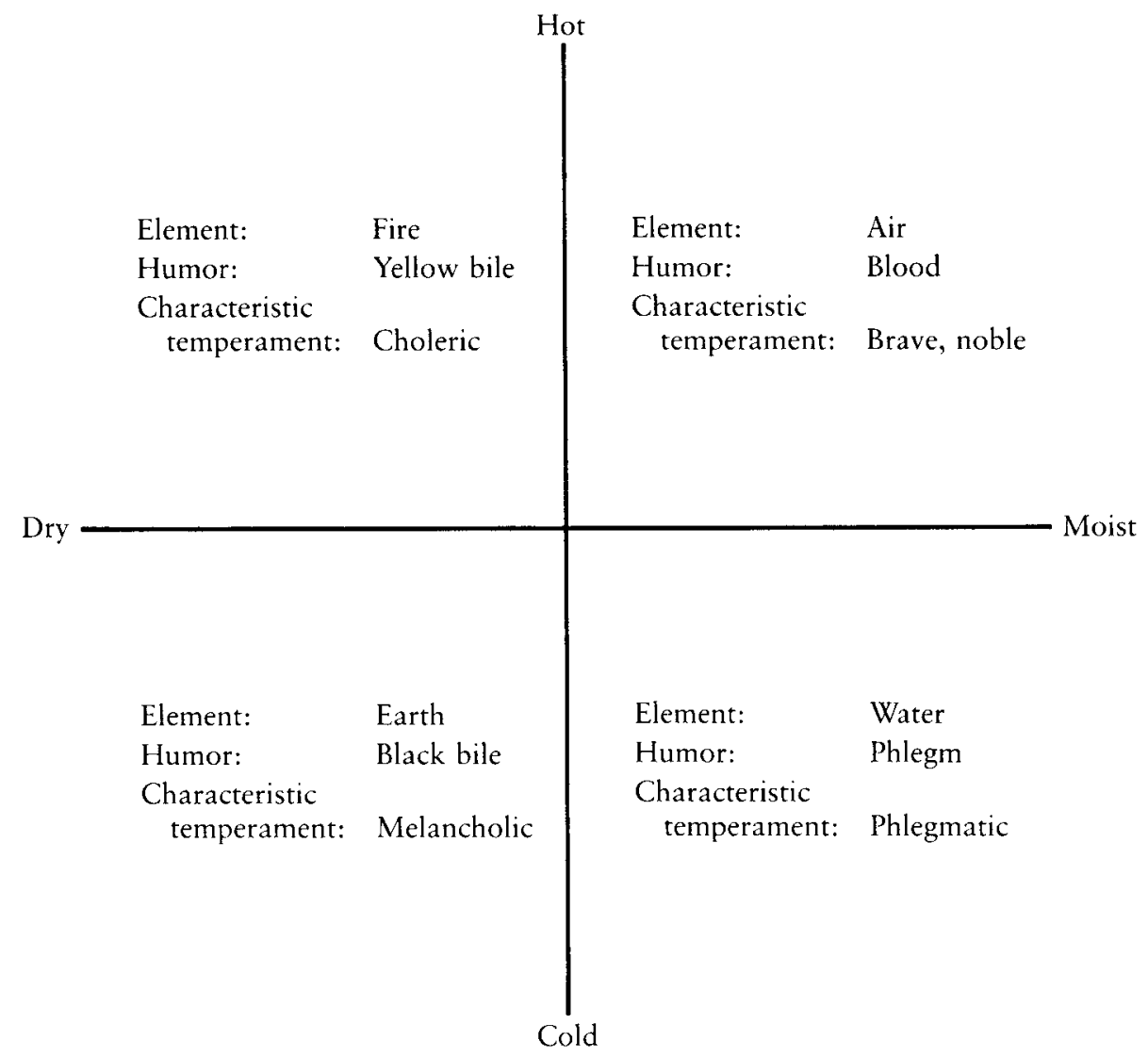

FIGURE I Elements, humors, and characteristic temperaments associated with combinations of the four qualities 
ior. The prevalence of blood (air, hot and moist) yields militancy and courage. When phlegm controls (water, moist and cold), passivity prevails; and the dominance of black bile (earth, cold and dry) causes melancholy. Many forces influence the balance of the humors, genealogy and the environment being the primary ones.

In antiquity the study of the humors and their causes and effects (termed physiologia physis) embraced the double meaning of "Nature" and the multiple "nature" of things. Nature and the multiple natures were assumed to have a logos, a harmonic reasonableness in them. Human logos was rational knowledge, among other things. Thus human logos attempted to understand and control the logos of $\mathrm{Na}$ ture and of natures. This activity was called physiologia-human logos seeking to understand and manage the logos of the physis. And this activity was based on an understanding of the elements and the humors.

To most Westerners, these concepts are vaguely familiar. Even though the language of biles and humors has become obsolete or at least archaic, the complex metaphorical relationships between hot and dry: fire and anger; hot and moist: blood and life; cold and moist: water and peace; and cold and dry: earth and melancholy remain intelligible. Indeed, they are found in ordinary speech to a surprising extent. Powerful literary associations and present-day assumptions about racial characters are based on them.

A basic characteristic of the humoral/environmental theory is its complex hierarchical quality. The universe is constructed of combined primary qualities, physically manifested as elements. All parts of the universe must have these constituents; they must be, in a sense, microcosms of the macrocosm. Differences between distinguishable physical things arise from the quantitative differences in the combinations of the elements of which they are formed. In the organic world the elements are manifested as humors, and the humors, depending on their quality and quantitative mixtures, determine behavior.

From top to bottom and from outside to inside, the universe is made up of varying combinations of four primary qualities. The differences between things reflect only the differing quantitative mixtures of these qualities in the form of elements and humors. 
The Environmental and Genealogical Principles

Explanation in this system is basically a matter of accounting for the composition of a particular thing, be it a planet, a rock, a human, a disease, or an emotion. The accounting can be done in two related ways. First, the physical conditions that prevailed at the place and time an entity originated can be used to explain its character-that is, direct environmental causation. For convenience I will call it the "environmental principle" of causation.

Alternatively, the character of an entity can be explained as an inheritance from its progenitors, whose initial traits were fixed through the operation of the environmental principle or by some act of special creation. I will call this the "genealogical principle" of causation. Together these two causal principles play a major role in the social, political, and moral extrapolations based on this theory.

\section{Humoral/Environmental Explanations}

These humoral/environmental views are exceedingly adaptable. Major Western developments in cosmology, geography, geology, biology, and medicine reflected the playing out of these basic doctrines for well over two thousand years. Since, in this view, the whole cosmos operated according to material principles that were everywhere the same, certain kinds of scientific research were given major encouragement.

At the same time, these views dictated the terms of major theological questions: What kind of creator would originate such a system and under what circumstances? Could there be anything more to a human being than the combination of four humors? To these questions there are innumerable answers. ${ }^{2}$

Humoral/environmental theories state that the universe is made up of qualities manifested as elements. All four of these elements, transformed into humors, are present in organic benings. Both the environmental principle (immediate physical causation) and the genealogical principle (inherited humoral constitution) are used to explain the way the outside world comes to be part of human beings. Persons are as 


\section{I Major Western Views of Nature}

they are because of where they were born or because of the characters of their parents.

An additional theory is needed to explain how the humors are generated within each human being, and medical history books review a festival of them. Perhaps the most popular view was that the primary humor is the blood: it is the blood that passes on from parent to child, providing the genealogical connection. Accordingly, the blood must somehow contain the other humors or assist in their creation out of elements the person incorporates from the environment. Each generation reproduces itself by means of the blood, which then reproduces the other humors.

Each human being has individual characteristics because of the combination of the humors within. This combination is given by the genealogical principle but is strongly affected by the immediate physical environment, as the subsequent discussion of Hippocrates will show. This dual action of the environmental and genealogical principles neatly sets the foundations of the nature/nurture debate still with us today.

How the parents come to have the particular combination of humors that characterizes them is partly a matter of the blood they received from their parents and partly a matter of their environments. Theorists weight these two factors differently, and arguments over this weighting are a constant feature of these debates. Except in a few extreme cases, so-called hereditarians and environmentalists are separated mainly by a matter of emphasis, a point that deserves more attention than it has received.

Logically implied in this approach to causation is the need for an original creation. The genealogies of entities have to originate somewhere at some time. If one wants to know why humans or for that matter any species has a particular set of characteristics, it is necessary to posit an original moment of creation when those features either first arose directly out of a specific environment or were simply created. Thereafter all history is simply the playing out of combined environmental and genealogical influences as they operate on the original template (constitution, "nature").

The close but ambivalent relationship between the environment and human characteristics is strongly emphasized in this view. Since hu- 
mans are composed of humors derived from the same elements that make up the surrounding physical/biological universe, humans are easily affected by environmental factors. As the texts of Hippocrates, Galen, and other early medical theorists show, a major part of medical practice had to do with the diagnosis of basic human constitutions and of environmental effects on them, and the elaboration of treatments that altered the internal composition of humors by applications of varying combinations of the elements to the body, either internally or externally.

While the environment leaves it stamp on the individual, the genealogical principle also insists that some of what an individual is comes from the parents, the parents' parents, and so on. Thus some aspects of the individual resist the influence of the local environment. People are as they are because of their ancestors; they "breed true."

This ambivalence between direct environmental causation-a view that is completely consistent with humoral/environmental theoryand genealogical causation, which is much more difficult to assimilate into the theory, is a basic feature of thought in this tradition. Genealogical causation is partly consistent with the theory in that the physical substance of an offspring is directly derived from that of the parent. The massive incorporation of the environment in the form of food and other local influences, however, makes the autonomy of these genealogically transmitted substances hard to maintain theoretically without a well-developed material explanation of heredity. We only now have such an explanation with modern genetics. In most versions of this idea, the genealogical principle is converted quickly into a kind of nonmaterial identity transmitted in the blood.

Given this ambivalence, the central analytical task involved in the application of the humoral/environmental theory to humans is to decide how much of the makeup of a particular person or group of people is caused by the immediate physical environment and how much is caused by the genealogical principle. To the extent that the local environment is a determining factor, a doctor or a ruler can alter the people by altering the environment (insofar as it is possible to do so) or can move the people to a more suitable location.

To the extent that the genealogical principle is a determining factor, a leader can only adjust institutions to suit the characteristics of the 
people, move them on an environment in which their genealogical traits in combination with the local environment will produce a desired result, or breed them to alter their traits. This is the nature/ nurture argument in its old suit of clothes. Current nature/nurture debates make it clear that little has been added to this view since Hippocrates' time.

The complexity and coherence of the humoral/environmental theory are intriguing. All things - the universe, the planets, animals, humans, individuals - are characterized by varieties of equilibria of their qualities, elements, and humors. The states of sickness and health in individuals vary because the equilibria of their humors vary. Medical treatment acts to restore balance. Individuals differ from one another because of their different personal equilibria. Sexes, races, and species differ for the same reasons that the seasons, periods of life, and periods of history differ. Groups of people in the same places are similar because of their environmentally caused similar humoral makeups. Members of the same families are similar because of their genealogically caused similar humoral constitutions. Thus similarities and differences between people are accommodated and explained by the same small set of principles. Evil, illness, aggression, bad government, and other problems are caused by disequilibria of the elements and humors. Social justice and peace are accomplished by a process of equilibration.

The humoral/environmental theory is thus a very broad theoretical framework for the explanation of the material, organic, and human world. While it cannot account for the initial creation of the categories of entities in the world, it does explain the development and current operation of the world and serves as a guide to conduct. It is thus a theory of great generality and utility.

"Airs, Waters, and Places"

A review of Hippocrates' "Airs, Waters, and Places" (I 886) indicates how the theory was actually used as an explanatory model for analyzing human behavior and as a guide to its alteration. Whether or not Hippocrates was a real person is the subject of learned debate. 
All that can be said with certainty is that there is a collection of medical texts dating from between 460 and 377 B.C. and that these texts are conventionally grouped under Hippocrates' name.

The famous treatise "Airs, Waters, and Places" is a combined medical handbook and theory of human history based on the analysis of the particular interactions between the elements and their humoral consequences in different environments. It begins with a typology of cities according to the kinds of airs that influence them. Cities exposed to hot winds typically give rise to humid diseases, while those exposed to cold winds produce hard and bilious diseases. The cities in which the west wind predominates combine hot and cold in an unhealthy way that leads to both bilious and febrile disease. Only cities exposed to both hot and cold winds are truly healthy human environments.

A similar typology of waters is elaborated. Marshy areas give rise to bilious diseases. Areas of rock springs cause diseases of hardness. Waters from elevated ground are best, as are waters from the east; those from the west are not bad; those from the north are poor; and waters from the south are extremely unhealthy. Water treatments are recommended for diseases caused by waters. Rainwater, for example, is used to counteract the influence of snow and ice. The treatise also argues that when unlike waters mix, the kinds of airs present will determine which water will prevail. The same system is used to deal with the four seasons. Each season is seen as a combination of temperatures, humidity, and wind-as the working out of the primary qualities in various combinations.

The text then compares Asia with the Mediterranean area in terms of the predominance of various airs and waters and their impact on the human inhabitants. In an overview the author argues that climates that experience great and rapid change give rise to the greatest amount of human diversity, while climates of little change promote human homogeneity.

Up to this point the environmental principle is absolutely paramount. Everything is directly caused by the action of immediate environmental features. But then the text breaks into a different line of argument. The genealogical principle appears and comes into conflict with the environmental principle. In Hippocrates' view, for example, 
the seasons are modifications of the "natural frame" of the population:

... with regard to the country itself, matters are the same there as among all other men; for where the seasons undergo the greatest and most rapid changes, there the country is the wildest and most unequal; and you will find the greatest variety of mountains, forests, plains, and meadows; but where the seasons do not change much there the country is the most even; and, if one will consider it, so is it also with regard to the inhabitants; for the nature of some is like to a country covered with trees and well watered; of some, to a thin soil deficient in water; of others, to fenny and marshy places; and of some again, to a plain of bare and parched land. For the seasons which modify their natural frame of body are varied, and the greater the varieties of them the greater also will be the differences of their shapes. [Hippocrates 1886:1707I; emphasis mine]

Having thus raised the possibility of divergence between the local environment and the genealogical principle, the text explores the mechanism by which environmentally caused factors could become part of the "natural frame" in a way that was not definitively challenged until Gregor Mendel's work gained full acceptance.

I will pass over the smaller differences among the nations, but will now treat of such as are great either from nature, or custom; and first, concerning the Macrocephali. There is no other race of men which have heads in the least resembling theirs. At first, usage was the principal cause of the length of their head, but now nature cooperates with usage. They think those most noble who have the longest heads. It is thus with regard to the usage: immediately after the child is born, and while its head is still tender, they fashion it with their hands, and constrain it to assume a lengthened shape by applying bandages and other suitable contrivances whereby the spherical form of the head is destroyed, and it is made to increase in length. Thus, at first, usage operated, so that this constitution was the result of force: but, in the course of time, it was formed naturally; so that usage had nothing to do with it; for the semen comes from all parts of the body, sound from the sound parts, and unhealthy from the unhealthy parts. If, then, children with bald heads are born to parents with bald heads; and children with blue eyes to parents who have blue eyes; and if the children of parents having distorted eyes squint also for the most part; and if the same may be 
said of other forms of the body, what is to prevent it from happening that a child with a long head should be produced by a parent having a long head? [P. I7I; emphases mine]

Humans can be changed by both nature and culture, all within the overall materialism of the humoral/environmental theory. Hippocrates asserts that semen comes from all parts of the body. By this assumption, it is then possible to state that the condition of any part of the body will be reflected in the humoral makeup of the semen that emanates from the part. This makeup, in turn, will be passed on to the next generation in the form of a permanent alteration of the humoral balance, turning cultural practice into a natural feature of a particular group of people.

This is as clear a statement as can be found of the explanation of the path by which external environmental influences become part of the constitutions of individuals. This argument is of crucial importance to later theories regarding the differentiation of races, nations, and constitutional types.

Later in his text Hippocrates shows the way this materialist theory may be reconciled with the existence of a creator:

\begin{abstract}
... there are many eunuchs among the Scythians, who perform female work and speak like women. Such persons are called effeminates. The inhabitants of the country attribute the cause of their impotence to a god, and venerate and worship such persons, every one dreading that like may befall himself; but to me it appears that such affections are just as much divine as all others are, and that no one disease is either more divine or more human than another, but that all are alike divine, for that each has its own nature, and that no one arises without a natural cause. [P. I78]
\end{abstract}

The natural and the divine explanations are compatible because deities created nature and thereafter it runs according to the principles set in motion upon its creation.

Toward the end of the essay Hippocrates turns to a more detailed analysis of character differences within the Mediterranean world. He argues that in high, varied, well-watered places, people are enterprising and warlike, while in low and ill-ventilated places they are fleshy, 
dark, and bilious. In high, flat, well-watered places, people are large and gentle, and in high, dry places, people are hard, blond, and haughty. Perhaps the most surprising thing about this last set of observations is how closely they conform to current ethnic stereotypes about regions within modern nation-states and about differences in national character.

These are the basics of the humoral/environmental theory. A complex, tiered system of thought that is immensely adaptable as an explanatory and classificatory framework, it provides the foundation for most of the arguments (and their internal contradictions) regarding relations between nature and culture before and, I believe, after Darwin.

\section{Natural Categories and the Chain of Being}

Humoral/environmental theories cannot account unaided for the creation of the categories of entities in the material world. Yet the observable world is filled with highly organized, diverse entities. Each seems to have a "nature"; each represents a species with characteristic structures and habits. Together these species form a reasonably harmonious whole. Why there are many varieties of entities, how they are organized, how they came into existence, the initial source of each, and the degree to which the set of species is complete or in process (progressive or degenerative) are fundamental questions left unanswered by humoral/environmental theories. The answers given to these questions are numerous, but they share certain basic features.

In the span of time separating Hippocrates from Darwin, humoral/ environmental theories were associated with various theories of creation and order. Some of the pre-Christian views attribute the categories and order of the material world to the action of a multiplicity of gods. Other conceptions center on single universal creative forces. The most influential view arose from Judeo-Christian thought, in which the God of Genesis became the source of the categories and structure of the material universe.

God creates the natural order. From the initial chaos God orders matter into the elements and then, one by one, fashions all species out 
of these elements. Further, God creates all beings in a definite system of interrelationship, with humans at the pinnacle. Once this creation is complete, the work is perfect and no further creation is possible. The orderliness, the marvelous structure of even the simplest being, and the complex relations among species all celebrate the divine plan.

The structure of this set of ideas was superbly analyzed decades ago by Arthur Lovejoy in The Great Chain of Being ([1936] 1976). This book remains the fundamental work on the subject. Lovejoy's exposition begins with the analysis of a fundamental tension in Plato's thought between other-worldliness and this-worldliness. By "otherworldliness" Lovejoy means not a belief in an afterlife but rather

the belief that both the genuinely 'real' and the truly good are radically antithetic in their essential characteristics to anything to be found in man's natural life, in the ordinary course of human experience, however normal, however intelligent, and however fortunate ... the human will, as conceived by the other-worldly philosophers, not only seeks but is capable of finding some final, fixed, immutable, intrinsic, perfectly satisfying good. ... Not, however, in this world ... but only in a 'higher' realm of being differing in its essential nature, and not merely in degree and detail, from the lower. [Lovejoy 1976:25-26]

This higher realm is the world in which the multiplicity of eternal Ideas resides, ideas of which the things of the natural world are but imperfectly realized copies. Lovejoy goes on to show the basic contradiction between devaluing the natural world and using it as an empirical source for the formulation of the eternal Ideas.

All categories of things in the natural world are imperfect manifestations of perfect and eternal Ideas, but these Ideas are not randomly organized. They are ordered in turn by an "Idea of the Idea," generally rendered by Plato and eventually by Christian theologians as the "Idea of the Good." Lovejoy handles it deftly:

$\ldots$ it is ... the most indubitable of all realities ... it is an Idea or essence ... in distinction from the particular and changing existences which in varying degrees participate in its nature; and ... it therefore has the properties common to all the Ideas, of which the most fundamental are eternity and immutability ... it is the polar opposite to 'this' world ... its true nature is therefore ineffable in the forms of 
ordinary speech ... the Form of the Good is the universal object of desire. [Pp. 40-4I; emphasis removed]

If this idea is accepted, then, as Lovejoy points out, two problems are left unsolved. First, it is not clear why the imperfect natural world should exist at all. And second, if the natural world must exist, what determines how many and what types of things must make it up? The answers to these questions set the relevant point of comparison between pre-evolutionary and evolutionary views of the organic world.

To explain why the natural world must exist, theologians argued that the perfectly good cannot envy anything not part of itself.

Its reality could be no impediment to the reality ... of beings other than it alike in existence and in kind and in excellence; on the contrary, unless it were somehow productive of them, it would lack a positive element of perfection, would not be so complete as its very definition implies that it is.... The concept of Self-Sufficing Perfection, by a bold logical inversion, was ... converted into the concept of a Self-Transcending Fecundity. [P. 49]

Once this idea is accepted, the question regarding the number of things the world must contain is easily answered. Since the perfectly good could not envy the existence of anything, the world must contain absolutely all possible kinds of things. The world must be completely filled with all the possible natural categories of things. This concept Lovejoy christened the "principle of plenitude."

And once the principle of plenitude is accepted, the question of the organization of things in this world is also easily resolved. Since the perfectly good is the universal object of desire, and the world of nature is an imperfect copy of it, then all things in the world are arrayed in a hierarchy from the lowest and most distant from the perfectly good to that which is closest to it. In addition, the principle of plenitude requires that there be no gaps in the hierarchy from the lowest to the highest, since the world would thus have less in it than it could have. This hierarchy of categories of things, animate and inanimate, is what came to be known as the "chain of being."

The humoral/environmental theories provide explanations about the way entities in the material world behave through analysis of their 
material constitutions. On this level the humoral/environmental explanation is consistently materialist, since the same principles are applied to molten lava and epileptic seizures. But the humoral/environmental theory cannot explain the existence of the categories of things in the world or the origin of their interrelationships. Each kind of stone, plant, animal, air, water, human, disease has its source in principles external to the humoral/environmental view. The source is the eternal Ideas of which the things of the world are only manifestations. Only when humoral/environmental theories are armed with this conception can they become a global explanatory framework.

Let us return for a moment to the contrast between the genealogical and environmental principles. At first it appears that humoral/environmental theories rest primarily on the environmental principle, but it quickly becomes apparent that the genealogical principle is equally important, because only through genealogy can the categories of entities in the world and their interrelationships be explained.

As a result, humoral/environmental theories are always riven by a conflict between the environmental and the genealogical principle. The ambivalence can be seen in Hippocrates' discussion of the long-headed Macrocephali and in his concept of the "natural frame" that is resistant to environmental influences.

The essences of things, the categories of the natural world, are given by the eternal Ideas. They pass from generation to generation by the genealogical principle. Their transmutations occur only as the result of the action of humoral/environmental principles, and these transmutational principles themselves are ultimately derived from eternal Ideas.

The conflict between the necessary genealogical principle and the primarily environmental bias of the humoral/environmental explanations can never be resolved. The nature/nurture debate is an intrinsic part of this view. It is not, however, intrinsic to modern evolutionary biology, and the persistence of the nature/nurture debate up to the present suggests just how powerful the hold of the ancient humoral/ environmental world view still is. 


\section{Evolving Natural Categories: Darwin's Unique Legacy}

The evolutionary world is a world in motion, in stark contrast with the static world of Hippocrates and the chain of being. At the very center of evolutionary thought is a view of the classification of living things so radically different from earlier views that it turns them inside out.

Though empirical investigation made a major contribution to the development of evolutionism, the Darwinian revolution cannot be understood as the simple result of such activities. Darwin's own view of the organic world seems to rest on a systematic inversion of the structure of earlier views, an inversion that then served as the source of his hypotheses for empirical investigation. Any approach that claims to be evolutionary must share certain elements of Darwin's vision of the world in motion. Many putatively Darwinian views do not.

The scholarship on Darwin and Darwinism is enormous and rich. ${ }^{1}$ The intense debates about the dating and sources of ideas are pursued by experts with lifelong commitments to the study of Darwin's texts. Radical reperiodizations of Darwin's thinking are currently taking place, particularly in light of the information contained in his notebooks 
(Gruber, ed., I974; Herbert, ed., I980). The young Darwin had developed the whole theory of classification and evolution much more fully than anyone reading The Origin of Species would imagine. Darwin's representation of himself as a mere accumulator of data that inexorably led him to the theory of evolution is now being questioned.

Despite the appreciation of Darwin's own work and general agreement on the revolutionary impact of evolutionism on biological, social, and moral thought, one crucial element is widely mentioned but still tends to be undervalued. Darwin proposed a radical revision in our understanding of taxonomic classification in biology and in the theoretical meaning of the various taxa within the system. Substituting genealogical for formal principles of classification, Darwin reorganized the system of classification to reflect descent with modification and to emphasize the productive role of variation in evolutionary processes. $^{2}$

\section{Culture and Classification}

The study of systems of classification is a major component of modern sociocultural anthropology. Beginning early with the study of the alternative means by which people in other cultures classify the world into "kin" and "nonkin" (thereby structuring their social relations in crucial ways), more recently passing on into the study of totemic classification systems (Douglas 1966) and the development of the entire field of structuralism and semiotics (Lévi-Strauss I962), and finally into the study of ethnoclassification (Berlin and Kay 1969), anthropologists have devoted immense energy to the analysis of systems of classification. In particular, structuralist and semiological approaches to the analysis of cultural systems as systems of classification have yielded fascinating results in the hands of Claude Lévi-Strauss, Mary Douglas, Edmund Leach, and many others. ${ }^{3}$

One of the most important results of these anthropological analyses is an increasing awareness of the close linkage between systems of classification and systems of morality. Any alteration in the major 
classifications of a cultural system nearly always implies alterations in moral systems as well. Put another way, there are no morally insignificant classifications. ${ }^{4}$

Seen in this light, the explosive reaction to Darwin, including the bitter questioning of his moral character, is not surprising. In proposing a revolution in the system of biological classification, evolutionism demolished part of the foundation of existing moral systems. This conflict accounts for the persistence of the essentialist/populationist debate in biology that Ernst Mayr (I982) so adroitly documents.

No evolutionist has stated the case better than Darwin did. It was his particular genius to have linked the question of evolution tightly to the issue of classification. But Darwin is no culture hero. He was wrong about many things, inconsistent about others; significant social biases invade his work. Many commentators, including Karl Marx, have claimed that Darwin's view of the evolutionary process was strongly conditioned by his social experience and position; that he was, in a word, an apologist for the capitalist order. Clear lines of evidence can be traced to show that Darwin held important social, racial, and sexual biases, though one becomes impressed by the moderation of his positions on these issues as one reads the works of many of his contemporaries.

Darwin was very much a man of his era, sharing many of its ideological biases. Yet no one has ever made the case for evolution better or with a clearer recognition of the immense scope of the intellectual revolution it proposes. In Darwin's key texts we are able to see clearly the revolution in classification that evolutionism implies. Perhaps better than any of his contemporaries and despite his ideological biases, Darwin believed that political and moral conclusions could not be derived directly from the study of evolution, a view exceptional even now.

Precisely because Darwin's works are so important, virtually every aspect of them has been subjected to close scrutiny. Much of this territory is hotly contested. Darwin's theories themselves, his social biases, his religious beliefs (or lack of them), and many other aspects of his writing and character are debated by experts. Little can be said about Darwin that will not be repudiated by someone. Such is his fate. 


\section{Darwin's Major Works}

The evidence Darwin used was available to all, and many of the conceptual structures were also in wide circulation. The secret of Darwin's success goes beyond his theoretical and empirical innovations. After all, both Darwin and his colleague Alfred Russel Wallace had come up with the theory of evolution. But it was through the writing of The Origin of Species that Darwin began the reversal of the predominant Western system of classifying nature and the construction of the theory of evolution out of that reversal. My emphasis on the reversal accounts for the highly selective reading of Darwin presented here.

I make no claims regarding Darwin's personal intentions. I do not know the thought process by which Darwin constructed his works. Rather I emphasize the internal logic of his system of thought as it supports the theory of evolution. The test of this kind of approach is simply how well it accounts for the structure, emphases, and data arrayed in the works.

\section{The Origin of Species}

Virtually everyone knows the story of the writing of The Origin of Species: the voyage on the Beagle, the coincidence of Darwin's and Wallace's views on evolution, the great stir Darwin's book created, and Darwin's subsequent problems and doubts. These issues are left aside here to concentrate on some of Darwin's statements about classification of plants and animals. Here his views contrast starkly with those of his predecessors and with those of many of his supposed followers as well.

The very title bears close scrutiny: The Origin of Species by Means of Natural Selection; Or the Preservation of Favoured Races in the Struggle for Life. The book is about the origin (in the sense of productive principle and genealogy), not the character, behavior, morphology, or embryology of species. It is about the origin of species, that is, how the categories of living things in the world of observation have come into existence-a process until then explained by the idea 
of special creation, which organized species into a chain of being, the species then being acted upon by humoral/environmental forces. The term "natural selection" is used because the causal agent in speciation is not God or any other supernatural principle that at some time in the remote past created eternal categories; it is the continuous operation of blind material laws.

The restatement of the subject-Or the Preservation of Favoured Races in the Struggle for Life-brings up an ambiguity that runs through Darwin's work and that of most other nineteenth-century thinkers: the terms "species" and "race" are often used interchangeably. In Darwin's case, the use of the term "race" is important because in ordinary speech "race" conveys a strong sense that genealogical principles are the primary ones that give rise to and define species boundaries. Species are separate categories of things in the world. To call them races is to emphasize the genealogical lines stretching from past to present and set the scene for the idea of descent with modification.

The "struggle for life" notion points to reproductive competion under specific environmental conditions as the mechanism by which natural selection operates. It is not a providential hand that chooses but blind physical laws, and the struggle never ends. Thus Darwin titled his book well, for the title summarizes his theory.

The book itself, despite Darwin's continual reference to it as an essay written in haste, has a coherent internal structure that supports the argument well. It is divided into three major setions, each dealing with a specific set of issues.

The first section is devoted to an exposition of the mechanisms that produce variation, competition, and ultimately speciation by means of natural selection. Darwin begins this section strategically by discussing variation under domestication. Since humans have induced speciation quite often by manipulating the environments and reproduction of plants and animals, how can we believe that species boundaries are absolute and fixed? Darwin also points out that species under domestication are highly variable. It is this variability that permits us to breed plants and animals as we do.

Variation is the centerpiece of Darwin's world view, and thus he begins with it. Where others saw uniformity and clear-cut species 
boundaries, Darwin saw ranges of variation. Much of his observational life was spent in cataloguing variation, a phenomenon that not only was theoretically important for him but clearly fascinated him in its own right. This focus contrasts sharply with the pre- and nonevolutionary views of the world, in which fixed natural categories of things succeed themselves from generation to generation, with no change other than some preordained progress or fateful degeneration.

Having made his argument about variation and selection in the world of everyday human experience, Darwin then moves outward to the undomesticated world, showing that a similarly great amount of variation exists in all living things. Examples abound, drawn from everywhere. Variation is the first step in the argument for evolution.

Darwin then introduces the "struggle for life." Outside the domesticated world there are no plant and animal breeders to act on variation. Darwin argues that different variants are differentially capable of reproducing successfully in the diverse environments in which they are found. Those better able to reproduce proliferate and the others fade away. This view is complemented by the naming and development of the concept of natural selection.

In Chapter I, humans were the selectors. Now Darwin opens up the possibility that blind natural forces act as selectors on the immense number of variants among plants and animals. This process of natural selection gradually changes the structure of species of plants and animals until new and different species come into existence, all genealogically linked to their predecessors. He closes the section with a chapter on "laws of variation," in which he claims that a theory based on variation and natural selection will yield a coherent interpretation of the history of life on earth.

The second section strategically poses the major objections that could be advanced to compromise his general argument. Here Darwin's capabilities as a scientific thinker become particularly manifest as he first conceptualizes the opposing views and then systematically undercuts them. He casts down the gauntlet in scientific fashion: this is the theory; here are all the objections to it; none of the objections is crippling, so until an unanswerable objection can be formulated, the theory stands.

In the third section Darwin arrays geological, geographical, and 
morphological evidence in support of the theory of evolution. With each body of evidence goes the suggestion that much more evidence could be adduced. The recapitulation of the whole argument at the end of the book shows, among other things, just how well planned this "essay" was. Throughout the book the movement is measured and self-conscious: argument, counterargument, proof, recapitulation.

Often using little and tenuous evidence, Darwin succeeded in making a forceful argument that species arise continuously by material processes, thereby demolishing the centerpiece of the pre-evolutionary views of nature. Darwin did not create an unrecognizable world of nature. Rather he took the world of nature as people observed it and explained its structure in a way that was odious to a significant part of his audience.

It is helpful to flesh out the argument about evolutionary classification put forward here with some of Darwin's specific statements. The Origin of Species begins with a criticism of the view of species as immutable and separate:

Until recently the great majority of naturalists believed that species were immutable productions, and had been separately created.... Some few naturalists ... have believed that species undergo modification and that the existing forms of life are the descendants by true generation of pre-existing forms ... [Darwin (1859) 1958:17]

An emphasis on genealogical relationships (what Darwin called "true generation") is the key to his argument against separate creation. Occasionally this emphasis on genealogical relationships leads him to appeal to the old language of "blood," as in the following case: “... looking to the domestic dogs of the whole world, I have ... come to the conclusion that several wild species of Canidae have been tamed, and that their blood, in some cases mingled together, flows in the veins of our domestic breeds" (p. 39). He contradicts the notion of separately created species by conjuring up genealogical relations between wild and domesticated dogs. If such genealogical relations exist, and the wild comes before and gives rise to the tame, then species are generated out of each other. 
Later Darwin links variation with speciation, in this case by speaking of domesticated species: "The key is man's power of accumulative selection: nature gives successive variations; man adds them up in certain directions useful to him. In this sense he may be said to have made for himself useful breeds" (p. 48 ).

This is a frontal attack on special creation. Nature itself is the producer of variation. In the pre-evolutionary view, nature merely reflected the initial order made by the creator. Humans produce species by acting on this variation; humans "create" species through selection. Such actions would be impossible in a world of hermetically sealed separate species. For Darwin, variation is not deviation from the ideal form of the species; it is the source of all species.

Darwin sums up this argument by stating:

Changed conditions of life are of the highest importance in causing variability, both by acting directly on the organisation, and indirectly by affecting the reproductive system. ... Over all these causes of Change, the accumulative action of Selection, whether applied methodically and quickly, or unconsciously and slowly but more efficiently seems to have been the predominant Power. [P. 57]

Thus by the end of his initial chapter Darwin has put most of the major elements of his argument into play. Beginning with the world of everyday observations of domesticated plants and animals and their variations, he moves outward toward larger principles. If humans, by controlling reproduction, can create species by selecting for certain variants, then species are not immutable. It is then conceivable that other agencies (such as the environment) could also select among the variants within an existing species and ultimtely cause the creation of new species. If this argument is accepted, separate creation and the chain of being disappear.

The central obstacle left for Darwin to overcome is the proof that variation and selection occur outside of the domesticated species directly subject to human agency. He turns to this task with vigor.

The argument begins with a strong emphasis on the arbitrariness of species boundaries. Darwin states: “. . . I was much struck how entirely vague and arbitrary is the distinction between species and varieties" (p. 63). Then he elaborates the argument: 


\section{2 | Major Western Views of Nature}

Certainly no clear line of demarcation has as yet been drawn between species and sub-species ... or, again, between sub-species and wellmarked varieties, or between lesser varieties and individual differences. These differences blend into each other by an insensible series; and a series impresses the mind with the idea of an actual passage. [P. 66; emphasis mine]

Darwin's view of the empirical world centers on variability, complexity, and classificatory ambiguity. He radically reverses the view of nature as a linked chain of sharply separable species with no motion other than self-replication. In place of fixed species Darwin inserts "an insensible series." In place of clear categories he interjects the arbitrariness of species boundaries. And in place of a series of similar but variant organisms he poses a historical, evolutionary relationship.

To counter the existing view of the natural world, Darwin attacked the dominant classificatory scheme. Rather than seeing species as eternal categories that empirically vary around the perfect expression of the species' inherent character, he makes variation the real and eternal feature of nature, converting species into momentary historical embodiments of these variations. In this massive reversal he subverts special creation and the chain of being at the same time. He creates a view a nature that is the opposite of the dominant one.

This argument logically leads him to the next questions: What agency causes the appearance of various species out of the multiplicity of variation observed in nature? Why is nature simply not an incoherent teeming of life? Many thinkers have attempted to reinsert the hand of God into the theory of evolution at this point by arguing that the whole process of variation and selection is providentially guided. Darwin did not take this path. Instead he insisted that the origin of species must be understood solely as a historical process with a beginning, operating according to coherent principles, but without an intrinsic direction or goal.

Defining the struggle for life, he says:

Owing to this struggle, variations, however slight and from whatever cause proceeding, if they be in any degree profitable to the individuals of a species, in their infinitely complex relations to other organic beings and to their physical conditions of life, will tend to the preservation of 
such individuals, and will generally be inherited by the offspring. The offspring, also, will thus have a better chance of surviving, for, of the many individuals of any species which are periodically born, but a small number can survive. I have called this principle . . . by the term Natural Selection, in order to mark its relation to man's power of selection. But the expression often used by Mr. Herbert Spencer of the Survival of the Fittest is more accurate. ... [P. 74]

Variation, complexity, multiplicity, and competitive advantage are the centerpieces of Darwin's view.

Why could God not create such a world? Darwin does not, in fact, dispute the existence of God, but he deeply distrusts human understanding of nature. Darwin's view of the physical limitations of the human mind and its capacity for experience in relation to the complexity and vastness of the physical universe makes him deeply suspicious of simplistic conceptions of the creator.

... so profound is our ignorance, and so high our presumption, that we marvel when we hear of the extinction of an organic being; and as we do not see the cause, we invoke cataclysms to desolate the world, or invent laws on the duration of the forms of life! . . He who believes that each equine species was independently created, will, I presume, assert that each species has been created with a tendency to vary, both under nature and under domestication, in this particular manner, so as often to become striped like the other species of the genus; and that each has been created with a strong tendency, when crossed with species inhabiting distant quarters of the world, to produce hybrids resembling in their stripes, not their own parents, but other species of the genus. To admit this view is, as it seems to me, to reject a real for an unreal, or at least for an unknown, cause. It makes the works of God a mere mockery and deception; I would almost as soon believe [with] the old and ignorant cosmogonists, that fossil shells had never lived, but had been created in stone so as to mock the shells living on the seashore. [Pp. 82, 155-56]

By emphasizing the diversity and complexity of the natural world, Darwin stresses a point he makes repeatedly in the Origin and later, in more detail, in The Descent of Man.

Darwin is very careful to argue that natural selection itself does not induce variation. Were he to admit that it did, variation would be 
easily reduced to a mere incident in natural selection, with evolution following directly from environmental requirements. As it is, his emphasis is just the opposite. There is hugely more variation available in the world than is operated on by selection. Variation is produced by principles that Darwin did not in fact understand, but he was certain that the cause was not the process of selection itself. Living nature's prime characteristic is production of variation; the production of temporary categories (species) is a subsequent step. The world moves dialectically from variation to selection to variation. Selection creates coherent classes of organisms.

Darwin argues that the crossing of varieties is a law of nature itself. If the chain-of-being argument were correct, then logically the best examples of a species would fertilize themselves. But Darwin's observations lead him

to believe that it is a general law of nature that no organic being fertilises itself for a perpetuity of generations; but that a cross with another individual is occasionally ... indispensable. On the belief that this is a law of nature, we can ... understand several large classes of facts ... which on any other view are inexplicable. [P. IOI]

Reproduction is mixing of variants.

Darwin reverses separate creation by considering the variations to be real and continuous and the species to be only momentary manifestations. He then argues that species breed in such a way as to produce rather than to reduce variation. Thus variation, not the fixity of species, is the "law of nature."

Darwin has chosen his words well, breaking the old meaning of "law of nature" from its mold as a description of a fixed order. He moves on a chain of rhetorical links from variation to domestication, breeding, and natural selection. At each juncture he challenges others to explain these facts better. Nature is a complex set of processes, a history with no goal. This is what Darwin's chart of species change emphasizes. (See Figure 2.)

When Darwin discusses the geological record, he strongly states his historical view of nature as in continual motion against the view of nature as consisting of a set of fixed, uniform categories. The constancy in nature is a constancy of motion: 

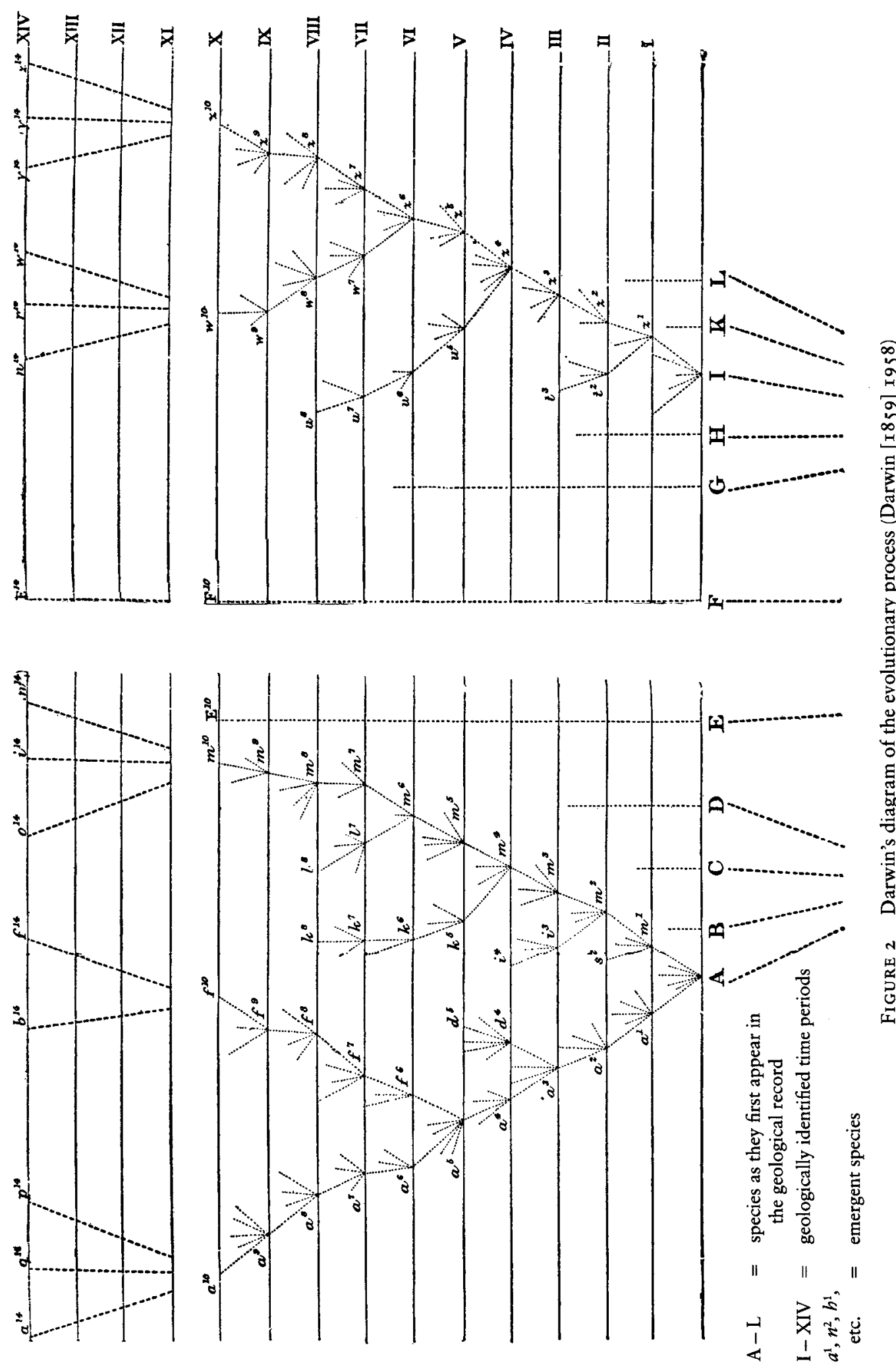
We can clearly understand why a species when once lost should never reappear, even if the very same conditions of life, organic and inorganic, should recur. For though, the offspring of one species might be adapted ... to fill the place of another species in the economy of nature, and thus supplant it; yet the two forms-the old and the newwould not be identically the same; for both would almost certainly inherit different characters from their distinct progenitors; and organisms already differing would vary in a different manner. [P. 3r 5 ]

The uniformity of causes imparts order to nature, but these causes work only through time. Each successive moment in the history of life is different from all other moments. This is a direct attack on the standard view of special creation.

Darwin shows his awareness that the issue of classification is the central one in evolutionary theory when he points to "the difficulties which are encountered on the view that classification either gives some unknown plan of creation, or is simply a scheme for enunciating general propositions and of placing together the forms most like each other" (p. 387). He points out that classifications are a complex mix of morphological and functional criteria; that embryological affinities not obvious in adult members of species are important in classifications; and that geographical distributions have also been important. Darwin insists, however, that there is only one correct overarching principle of classification. It must be followed, with all other principles subordinated to its requirements:

I believe that the arrangement of the groups within each class, in due subordination and relation to each other, must be strictly genealogical in order to be natural; but that the amount of difference in the several branches or groups, though allied in the same degree in blood to their common progenitor, may differ greatly, being due to the different degrees of modification which they have undergone; and this is expressed by the forms being ranked under different genera, families, sections, or orders. [P. 39I; emphases his]

Note that he says the arrangement must be "genealogical in order to be natural." Nature is defined as a historical process, and all classifications that are to aid in clarifying this natural process must be based on historical relationships. Darwin does not deny that classification 
can be done on numerous grounds, but he does deny that any but a genealogical classification can be used as the basis of an evolutionary analysis.

There is no question that the reaction to The Origin of Species was appropriate. The shock, excitement, and outrage were fully earned by such a frontal attack on the basis of existing views of nature. The Origin is a polemic. Despite its often ponderous apparatus of facts and its flat language, its central structure is provided by a reversal of the Western view of nature, supported by an appeal to scientific appraisal of the "facts," to the value we attach to the scientific method and rational analysis.

The principal issue he did not attack directly was that of human evolution. The only reference to it is the famous cryptic line "Much light will be thrown on the origin of man and his history" (p. 449). But no one could doubt what Darwin had in mind. If special creation and the chain of being had given humans a privileged place in nature, then a repudiation of those views must also alter the human position. It did, though his full statement of the point was not published until I $87 \mathrm{I}$, under the title The Descent of Man and Selection in Relation to Sex.

\section{The Descent of Man and Selection in Relation to Sex}

The Descent is a remarkable work both for the currency of its arguments and for the relative obscurity into which it has fallen. While The Origin is available in a variety of popular editions, until I98I the Descent was for a long time available only in expensive facsimiles. Thus its readership has been quite limited, though the general public has made best-sellers of other books on the same general topic (Lorenz [1963] I 971, Morris 1969, Ardrey 1966).

Evolutionary analysis applied to humans and the theory of sexual selection appear together in the Descent because Darwin believed that natural selection was much relaxed in the human case. In its place, sexual selection, heightened by human cultural capacities for its elaboration, is seen as a prime force. Darwin uses sexual selection to explain, among other things, the phenotypic diversity of human "races."

At each point in the long argument, humans are shown to be influ- 
enced by the same forces that are at work in the rest of the natural world. Thus the Descent closes out the hope that a unique realm of natural laws might be preserved that would maintain the special dignity of human beings.

Darwin emphasizes human variability just as strongly as he emphasized the variability of nonhuman life in the Origin. "The variability or diversity of the mental faculties in men of the same race, not to mention the greater differences between men of distinct races, is so notorious that not a word need here be said. So it is with the lower animals" ([I87I] I974:26).

After making some remarkably contemporary-sounding comments to the effect that humans are like domesticated animals in our variability, in the way selective forces affect us, and in that we are a highly diverse, wide-ranging species, he argues that human superiority is a direct result of our success in the struggle for existence:

Man in the rudest state in which he now exists is the most dominant animal that has ever appeared on this earth. He has spread more widely than any other highly organized form; and all others have yielded before him. He manifestly owes this immense superiority to his intellectual faculties, to his social habits, which lead him to aid and defend his fellows, and to his corporeal structure. The supreme importance of these characters has been proved by the final arbitrament of the battle for life. Through his powers of intellect, articulate language has been evolved; and on this his wonderful advancement has mainly depended. [Pp. 46-47]

After these generalities, Darwin focuses the argument on each of these traits in turn: intellectual faculties, social habits, body structure. Regarding mental faculties he says:

My object ... is to show that there is no fundamental difference between man and the higher mammals in their mental faculties.... As no classification of the mental powers has been universally accepted, I shall arrange my remarks in the order most convenient for my purpose; and will select those facts which have struck me most with the hope that they may produce some effect on the reader. [P. 64]

Regarding social living, Darwin argues that social habits and social control depend on the animal's ability to sense the approval and dis- 
approval of its conspecifics. He calls this capacity "sympathy" and claims that it also evolved by natural selection. All social animals have it, but humans have it in a higher degree. Darwin thus erases the line between human and nonhuman.

In the course of his argument Darwin explores the notion that different environments act as spurs to different kinds of cultural systems, especially the idea that challenging environments stimulate great activity and industriousness. He advances a number of eugenic arguments as ways of seeing natural selection at work on the populations of "civilized" societies, though his position is moderate by comparison with Francis Galton's hard line ([I869] I962). According to Darwin, the instinct of sympathy-the instinct to act in accordance with our understanding of the effect our actions will have on other peopleis the basis of our social existence. It prohibits us from taking positive eugenic measures against the weak.

After delivering the judgment on the animal affinities and genealogy of humans for which Darwin is so famous, he attempts to replace absolute human superiority with a sense of the majesty of life itself:

Thus we have given to man a pedigree of prodigious length, but not, it may be said, of noble quality. The world, it has often been remarked, appears as if it has long been preparing for the advent of man: and this, in one sense is strictly true, for he owes his birth to a long line of progenitors. If any single link in this chain had never existed, man would not have been exactly what he now is. Unless we willfully close our eyes we may, with our present knowledge, approximately recognize our parentage; nor need we feel ashamed of it. The most humble organism is something much higher than the inorganic dust under our feet; and no one with an unbiased mind can study any living creature, however humble, without being struck with enthusiasm at its marvelous structure and properties. [P. I6I]

When Darwin takes up the vexed question of race, he remains true to his principles. He begins by returning to the general argument that the question of race must be very ambiguous if even species boundaries are fuzzy. He then states that the question whether the races are species or not cannot be solved in the absence of a general definition of species that is accepted by all biologists. Lacking such a definition, he argues that 
although the existing races of man differ in many respects ... yet if their whole structure be taken into consideration they are found to resemble each other closely in a multitude of points. Many of these are so unimportant or of so singular a nature, that it is extremely improbable that they should have been independently acquired by aboriginally distinct species or races. The same remark holds good with equal or greater force with respect to the numerous points of mental similarity between the most distinct races of man.... The great variability of all the external differences between the races of man, likewise indicates that they cannot be of much importance; for if important, they would long ago have been either fixed and preserved, or eliminated. In this respect man resembles those forms, called by naturalists protean or polymorphic, which have remained extremely variable, owing, as it seems, to such variations being of an indifferent nature, and to their having thus escaped the action of natural selection. [Pp. 174, 193]

To account for the great differences among the races, Darwin turns to the principle of sexual selection. He views the development of highly distinctive morphological and behavioral characteristics primarily as means of attracting mates.

The work concludes with the following summary:

The main conclusion here arrived at, and now held by many naturalists who are well competent to form a sound judgement, is that man is descended from some less highly organized form. The grounds upon which this conclusion rests will never be shaken, for the close similarity between man and the lower animals in embryonic development, as well as in innumerable points of structure and constitution, both of high and of the most trifling importance ... are facts which cannot be disputed. They have long been known, but until recently they told us nothing with respect to the origin of man. Now when viewed by the light of our knowledge of the whole organic world, their meaning is unmistakable. The great principle of evolution stands up clear and firm, when these groups of facts are considered in connection with others, such as the mutual affinities of the members of the same group, their geographical distribution in past and present times, and their geological succession. It is incredible that all these facts should speak falsely. He who is not content to look like a savage, at the phenomena of nature as disconnected, cannot any longer believe that man is the work of a separate act of creation. [Pp. 601-2; emphasis mine] 
The brutality of his last line is stunning. The choice we are left with is to be primitives and believe in special creation or to be civilized and try to make do with evolution and find new sources of species pride.

At the very end the book adopts an uneasy balance between a view of our social obligations to educate people as far as possible (because increasing intellectual awareness necessarily improves moral judgment) and Darwin's laissez-faire view of society as an arena of free social competition. The book contains many tensions of this sort. There are lapses into racist doctrines; there is a good deal of overt and covert sexism; eugenics is toyed with. Yet by comparison with such contemporaries as Spencer and Galton, Darwin was very cautious on these issues-more ready than they to accept responsibilities for the protection of the weak than to use evolutionary doctrines to justify the suppression of the poor and the defenseless among us, and less willing to derive his ethics from the study of biology.

\section{Evolving Natural Categories}

My contentions are simple, perhaps even uncontroversial. I have argued that Darwin was a true scientific revolutionary. If one takes the view of nature (and of humans) that supports the theory of special creation and the concept of the chain of being and reverses all their central postulates, one comes up with a view very much like Darwin's. Whether or not Darwin consciously engaged in such an inversion in immaterial. What matters is that conceptualizing Darwin's work this way permits us to understand its revolutionary impact and to set the minimum requirements that any view of humans that claims to be evolutionary must meet.

The theories of special creation and the chain of being demand acts of creation that give rise to all categories of living things. These categories have definite natural boundaries. What variation there is among them is due solely to the influence of environments and, in the case of humans, to sin. Nature has no history, if history is conceived as a continual, open-ended causal process. At most an idea of progress or 
degeneration can be inserted in an attempt to make history dynamic without doing violence to the idea of special creation.

The special-creation view requires a fixed, absolute hierarchy of separately created species. The order of hierarchy is set by the sequence of creation laid out in Genesis. At the end of the sixth day of creation there is a day of rest. A radical break occurs when Adam and Eve are expelled from the Garden of Eden; now secular historical time begins. But this secular time has no capacity to bring about any alteration in the separately created categories. Each and every creature in every successive time period is simply the reincarnation of its species as that species was originally created. (See Figure 3.) To the extent that there is a genealogical relationship between time periods, it simply stretches back to the first created individual of the species. Any variability observed in any of the time periods is seen as deviation from the created ideal, deviation caused by environmental effects or by degeneration.

In this view, the core element is the idea that plants and animals breed true. As a first principle, humoral/environmental theories assert that there are direct physical principles of causation that operate in harmony throughout the physical universe. The second principle is that a first creation had to occur in a specific environmental context and this creation gave rise to the species constitutions that thereafter have passed through time almost intact. Reproduction in this view means copying. The environmental and genealogical principles interact by special creation, giving rise to the genealogical lines that are acted on by the environment to cause deviation from the norm. Variation here is equated with deviation. There is no link back between variation and the creation of species. The development of acquired characteristics can be incorporated in such theories only by means of radical internal inconsistency.

The fixity of these natural categories is the basis for moral judgments as well. Genesis and the chain of being not only show that creation is a one-time, orderly act; they also argue that the levels of existence are ranked, with humans at the pinnacle. Human relations with nonhuman nature and with our own biological existence are orchestrated by the hierarchy of the original creation. There is no historical dynamic, no change, no possibility whatever of evolution. 


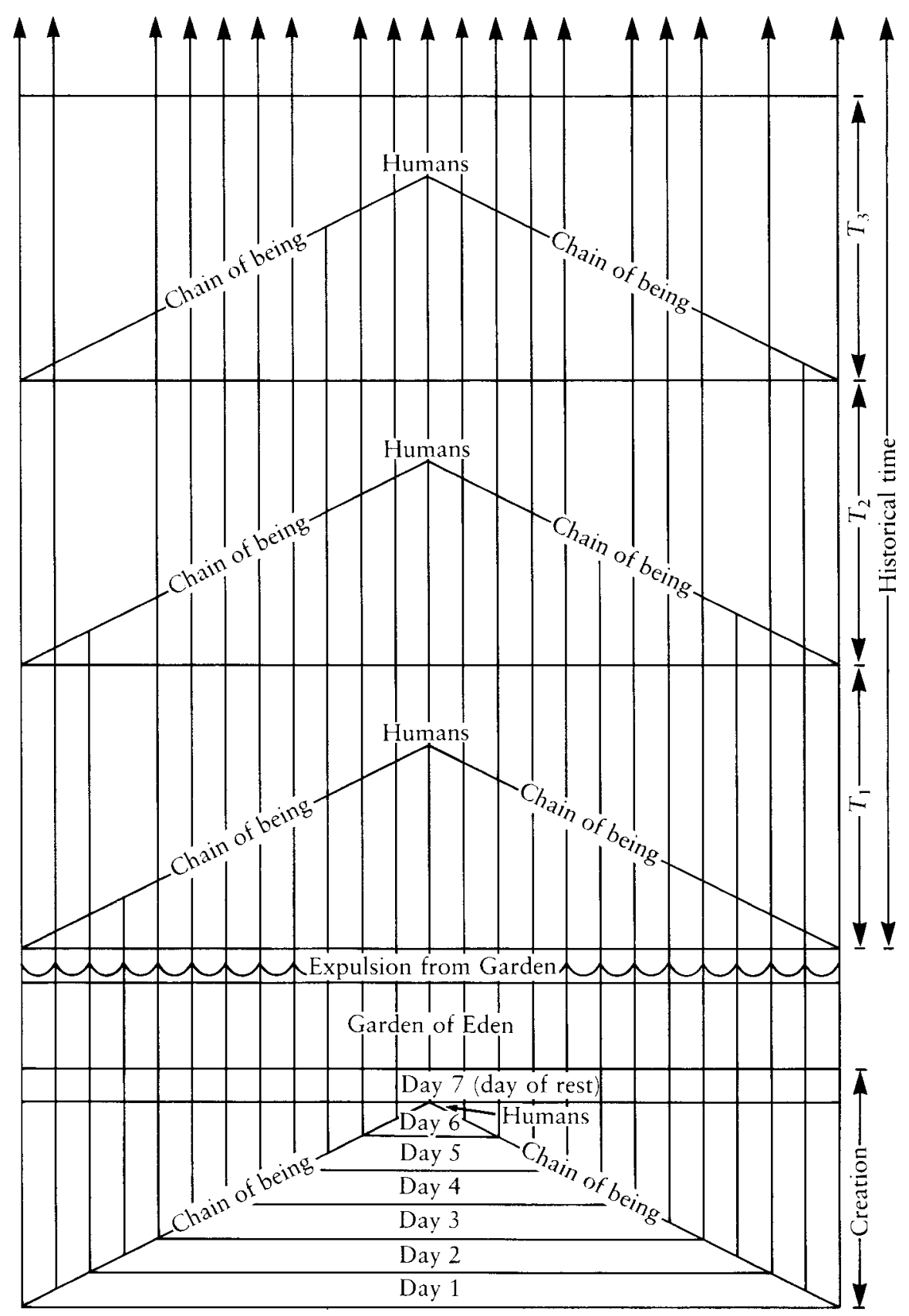

FIGURE 3 The chain-of-being view of the history of life 
Darwin attacks all of this scheme. In his view there is no single act of creation. The living world is in continual flux. Everything varies, all variations intergrading into each other. The emergence of natural categories (species) is an outcome of the interplay between chance variation and the selection processes that act on that variation in the "struggle for life." Species continually emerge out of the flux, as it were, and eventually disappear. Their historical contribution, however, is real. Every step in the genealogy of a current species bears the mark of its evolutionary history. The process as a whole is going nowhere in particular; it is simply going on. This history of life is the history of coming into being and extinction of species, nothing more and nothing less.

In the Darwinian view, the principal observation is the primacy of variation and speciation. For Darwin the first principle is the genealogical one. Each genealogical line produces spontaneous variations. These variations often mix with related lines. Here reproduction is equated with mixing and the production of variation.

The second principle is environmental, for the environment acts on the variations to select among them. In this case genealogy produces the variance and the environment selects among variants in a dialogue that causes continual speciation and extinctions. There are no fixed categories in nature.

The Darwinian revolution is apparent when Darwin's view is compared with the special creation view (which is after all what Darwin was doing). Both explanations have a beginning. Special creation begins when God said, "Let there be light"; the evolutionary view begins with the first emergence of some unicellular (or simpler) form of life. In both, in any time period, the various taxa can be ranked according to their formal complexity. In the special-creation view, however, the most complex taxon, humans, has dominion over the earth, while in the evolutionary view, higher taxa are simply higher taxa and no more.

The relationships between the time periods in the two views are quite different. After the initial creation in the Genesis view, each successive time period basically reexpresses the initial categories, except for certain extinctions (as in the Flood). By contrast, the relationship 
between time periods in the evolutionary view is a genealogical relationship in which current taxa develop out of previous ones. Some are extinguished and the rest become gradually transformed by the evolutionary process.

The two views place morality in very different contexts. The doctrine that underlies the idea of special creation is that "what is, is good" because it was designed by God. The doctrine of evolutionism is that "what is, is." For evolutionists, moral imperatives do not arise from the contemplation of natural categories that God created once and for all. Moral imperatives must be drawn from elsewhere; biology cannot be the handmaiden of ethics.

The environment plays a radically different role in the two views. In the special-creation view, the deity precluded the possibility of speciation. Differing environments work on fixed species to create variance in each generation's expression of the ideal category. In the evolutionary view, by contrast, variance is continuously produced by nature itself. The action of the environment on the variance actually produces the species, the natural categories.

For the special creationists, only the categories given by God's design are real. Each generation simply reincarnates them. For Darwin, only the facts of variance and selection are real (in the sense of being constant features of life on the planet). Species are simply the transitory embodiments of the results of this opportunistic, statistical process.

Even the observer's point of view is not absolute. Darwin argued that all perception is relative to the material structures that do the perceiving. Thus even our knowledge of evolution is conditioned by the structure of our own perceptual apparatus, itself a product of evolution. The special creationists, by contrast, must believe that perception of the absolutes in the design that lies behind the world of variable appearances is possible and that the human mind is capable of it.

Thus evolutionism not only demotes humans to kinship with the other animals but also eliminates our absolute godlike perceptual distance with regard to the everyday world of existence. The "facts" of observation and history are all we can deal with; our greatest hope is 
to understand where we come from. In place of a world of bounded natural categories and clear moral interpretations, evolutionism places only awe and curiosity.

The Minimum Standards for an Evolutionary View of Living Things

Darwin's views created an enormous stir in the scientific community, and many subsequent thinkers have proclaimed themselves to be ardent evolutionists. But not all evolutionists agree about the implications of Darwin's ideas, and some patently non-Darwinian ideas have found their way into the biological and social sciences, as Mayr has pointed out (I982). For this reason, it is necessary to set certain minimum standards that a theory must meet if it is to be considered evolutionary.

In order to be evolutionary, a theory must embody the following propositions:

I. Variation is a ubiquitous feature of all living things. It is continually and normally produced spontaneously.

2. Selection is the result of the interaction of specific sets of environmental conditions with the variations in species of plants and animals. Selection is the force that gives rise to and alters the categories of living things.

3. The interaction between variation and selection results in adaptation or extinction. Adaptation is always relative to particular organisms and specific environments. Adaptation is never permanent.

4. All forms of life are ultimately related to each other by genealogical connections.

5. There are no nonmaterial forces at work in the evolutionary process, nor are there any "pull" factors in evolution.

6. There is no radical dichotomy between humans and other animals (between "culture" and "nature"), just as there are no radical dichotomies between any things in nature at all. Species are ranges of variation that intergrade into each other at the margins. 
Though Darwin's works can be used to set standards for evolutionary thinking, they are by no means free of problems. Darwin lacked knowledge of the mechanisms of heredity and concocted the theory of pangenesis to support his argument. His stress on the absolute, slow uniformity of the pace of the evolutionary process was probably too extreme.

His views about society turned out to be incautious, though they were by no means outrageous in comparison with those of many of his popular contemporaries. His view of society as a natural and fair competitive arena and his thoughts on male dominance and eugenics now appear painfully naive and even hateful.

Of course evolutionary controversies continue. The phenotype/genotype distinction, the units of evolution-especially above the species level and below the individual level (i.e., biochemical processes)-the question of whether or not adaptation leads to optimum solutions, and the old chestnut about the direction of evolution are issues that continue to call forth heated debate. Yet what impresses one most in reading the literature produced by such contemporary evolutionary biologists as Ernst Mayr, Sewall Wright, Richard Lewontin, and Stephen Jay Gould is the degree to which Darwin's basic vision remains viable well over a century after its first public expression.

The controversies in modern evolutionary biology are important and lively. While some tenets of evolutionary thinking are agreed upon, mechanisms and interpretations are hotly debated. Exclusive attention to these contested issues in recent decades has led attention away from some larger questions about the acceptance of evolutionism, questions that only recently have begun to surface again.

The literature on racism and eugenics has been shown to contain numerous attempts to claim the support of evolutionary theory and other scientific views for a variety of oppressive doctrines (Chase 197576). The continuities between pre-evolutionary and current views on these issues are depressingly apparent and are well known. But other kinds of continuities exist.

Recently evolutionary biologists who approach the problem in very different ways have begun to argue that elements of pre- and nonevolutionary thinking are much more important in modern biology than current practitioners imagine. Mayr, in The Growth of Biologi- 
cal Thought (1982), distinguishes between "essentialist" thinking (what I have described as humoral/environmental theories) and "population" thinking (evolutionary reasoning). Mayr contends that the rise of evolutionism involves the replacement of essentialism by population thinking. The conflict between these two views, however, is of long standing in the Western intellectual tradition, and it continues to plague modern evolutionary biology. Though Mayr's agenda in contrasting these two traditions is somewhat different from mine, his view of the history of biology closely supports my characterization of the differences between pre- and nonevolutionary views of nature and evolutionary ones.

Another major trend in recent biological thought is the critique of "adaptationism." This critique has not been connected to the historical and interpretive issues I am emphasizing, but I am convinced that it can and should be. The adaptationist critique is most closely associated with Gould and Lewontin, who criticize certain contemporary biologists for introducing an adaptationist view into their evolutionary thinking:

... the adaptationist programme, or the Panglossian paradigm ... is rooted in a notion [of] the near omnipotence of natural selection in forging organic design and fashioning the best among possible worlds. This programme regards natural selection as so powerful and the constraints upon it so few that direct production of adaptation through its operation becomes the primary cause of nearly all organic form, function, and behaviour. ... An organism is atomized into 'traits' and these traits are explained as structures optimally designed by natural selection for their functions. . . . After the failure of part-by-part optimization, interaction is acknowledged via the dictum that an organism cannot optimize each part without imposing expenses on the others... .

The adaptationist programme can be traced through common styles of argument...

(I) If one adaptive argument fails, try another....

(2) If one adaptive argument fails, assume that another must exist....

(3) In the absence of a good adaptive argument in the first place, attribute failure to imperfect understanding of where an organism lives and what it does....

(4) Emphasize immediate utility and exclude other attributes of form. . . . [Gould and Lewontin I 979:584-87] 
From these premises Gould and Lewontin go on to argue that these fallacies in action result in the telling of "adaptive stories" that are immune to test.

Gould and Lewontin are combating a form of biological reasoning that reproduces important elements of the pre-evolutionary design argument. Perfect adaptation as an assumption belongs nowhere in evolutionary biology. It does, however, fit into the concepts of nature found in the design view, the special-creation theory, and some applications of humoral/environmental theory. Fixed species, clear natural categories, and perfect adaptations are the antithesis of evolution.

To use biological science to tell stories about a world in which all the organic parts are at an adaptive optimum is in effect not to use biological science at all, but to reintroduce teleology and theology into the study of the organic world. It is quite consistent with general attempts to domesticate Darwinism's randomized, liminal world in motion and render it less fearsome.

Together the works of Mayr, Gould, and Lewontin show that even within modern evolutionary biology, significant strains exist. The conflict between evolutionary and nonevolutionary views of nature has not come to an end with the "modern synthesis." 
